Educação ambiental e o ecoturismo na Serra da Bodoquena em Mato Grosso do Sul Fernando Machado Klein, Juliana P. de Oliveira Escandolhero, Nilce Romero Lucchese, Mercedes Abid Mercante, Silvio Fávero, Silvio Carlos Rodrigues

\title{
EDUCAÇÃO AMBIENTAL E O ECOTURISMO NA SERRA DA BODOQUENA EM MATO GROSSO DO SUL
}

\section{Environmental education and the ecotourism in the Serra da Bodoquena in Mato Grosso do Sul}

Fernando Machado Klein

Mestrando de Meio Ambiente e

Desenvolvimento Regional Anhanguera UNIDERP

Campo Grande/MS - Brasil fmklein@ipcms.com.br

Juliana P. de Oliveira Escandolhero

Mestrando de Meio Ambiente e

Desenvolvimento Regional Anhanguera UNIDERP

Campo Grande/MS - Brasil juliana_escandolhero@yahoo.com.br

Nilce Romero Lucchese Mestrando de Meio Ambiente e Desenvolvimento Regional Anhanguera UNIDERP

Campo Grande/MS - Brasil

nilcelucchese@gmail.com

Mercedes Abid Mercante

Professor, Doutor, Orientador Anhanguera UNIDERP

Campo Grande/MS - Brasil mercedes@terra.com.br

Silvio Fávero

Professor, Doutor, Orientador Anhanguera UNIDERP

Campo Grande/MS - Brasil sfavero@bol.com.br

Silvio Carlos Rodrigues Instituto de Geografia - UFU

Uberlândia/MG - Brasil silgel@ufu.br Artigo recebido para publicação em 03/05/2011 e aceito para publicação em 04/06/2011

RESUMO: $\quad$ O estudo da interrelação da prática do ecoturismo com a educação ambiental na região da Serra da Bodoquena, em Mato Grosso do Sul, especificamente os municípios de Bonito e Jardim, constituem o objeto deste artigo. A relevância do estudo justifica-se pelo fato da Serra da Bodoquena encontrar-se 
na Bacia Hidrográfica do Rio Miranda, ocupando uma posição estratégica para a conexão dos biomas Mata Atlântica, Cerrado e Pantanal. O trabalho de campo realizado demonstrou que a diversificação dos locais pode ser interpretada mediante observação e experimentação, por especialistas de diferentes áreas do conhecimento, sendo um campo vasto para o desenvolvimento de inúmeras pesquisas. Assim, com o levantamento in loco das principais características ambientais dos atrativos turísticos: Buraco das Araras, Gruta do Lago Azul, Baía Bonita e Rio Formoso, procedeu-se a análise da prática do ecoturismo e sua vertente educacional. Verificou-se, a necessidade de intensificação de ações educacionais, principalmente, aos guias turísticos, tendo em vista serem os principais indutores e difusores de informações relativas ao meio ambiente, bem como a realização de estudos dos percursos ofertados nos atrativos, com respectiva avaliação do potencial educativo e mapeamento da caracterização e adequação para diferentes públicos de visitantes.

Palavras-chave: Meio Ambiente. Relevo cárstico. Atrativos turísticos.

ABSTRACT: The study of the interrelationship of ecotourism with environmental education in the region of Serra da Bodoquena, state of Mato Grosso do Sul- Brazil, specifically in the cities of Bonito and Jardim, is the subject of this article. The relevance of the study is justified due to the fact of Serra da Bodoquena is located in Rio Miranda Hydrographic Basin, occupying a strategic position for connection of biomes: Atlantic Forest, Cerrado and Pantanal. The field research showed that diversification of sites observed can be interpreted through observation and experimentation by experts from different fields of knowledge, being a vast field for the development of numerous studies. Then, by on-site survey of the main environmental characteristics of tourist attractions: Buraco das Araras, Gruta do Lago Azul, Baía Bonita and Rio Formoso, proceeded to the analysis of practice of ecotourism and its educational aspect. It is therefore the need for intensification of educational actions, especially for tourist guides in order to be the main inductors and distributors of information relating to the environment, as well as the realization of attractive studies related to journey offered in attractive, with their assessment of the educational potential of mapping of characteristics and suitability of their different visitors.

Keywords: Environment. Karst. Tourist attractions.

\section{INTRODUÇÃO}

Uma das maiores críticas à prática do turismo para o desenvolvimento se deve ao fato de que suas modalidades têm trazido imensos impactos negativos para o núcleo receptor, tornando-se extremamente questionável a sua implementação, levando em consideração os desgastes das áreas naturais que são utilizadas como recurso e/ou atrativo turístico. (WEARING; NEIL, 2001).

O ecoturismo praticado no Brasil é uma atividade ainda desordenada, impulsionada, quase que exclusivamente pela oportunidade mercadológica, deixando a rigor de gerar os benefícios socioeconômicos e ambientais esperados. (SALVATI, 2001).
Embora o trânsito de pessoas e transportes possa ser impactante aos ecossistemas, é possível que a prática do ecoturismo contribua para a preservação dos mesmos quando aliada com a educação ambiental, podendo auxiliar no processo de desenvolvimento sustentável do local.

No estado de Mato Grosso do Sul, através dos dispositivos legais e normativos, o ecoturismo é definido como o segmento da atividade turística que utiliza de forma sustentável o patrimônio natural e cultural, incentivando sua conservação e buscando a formação de uma consciência ambientalista através da interpretação do ambiente, promovendo o bem-estar da população. (Lei Estadual 2.135/2000). 
A política para o desenvolvimento do ecoturismo no Estado tem como um dos seus objetivos a promoção do aproveitamento do mesmo como veículo de educação ambiental para turistas, comunidades locais e empreendedores do setor, acadêmicos e alunos. Prevê, ainda, o desenvolvimento da educação ambiental por meio da sensibilização de turistas e populações locais para a proteção do ambiente, do patrimônio histórico e dos valores culturais.

Na região de Bonito, o ecoturismo vem se difundindo como uma das principais atividades econômicas, tendo a necessidade de conservação da paisagem natural, da biodiversidade e geodiversidade como elementos de atração turística.

Nesse caso, admite-se que a educação ambiental está ligada à prática do ecoturismo assim como o ecoturismo está ligado a fatores de desenvolvimento sustentável que necessitam de planejamento, gestão e uma política considerada de alcance para os setores governamentais, as representações da sociedade civil e à iniciativa privada.

A educação ambiental é entendida como os processos por meio dos quais o indivíduo e a coletividade constroem valores sociais, conhecimentos, habilidades, atitudes e competências voltadas para a conservação do meio ambiente, bem de uso comum do povo, essencial à sadia qualidade de vida e sua sustentabilidade. Tem como princípios básicos, além de outros a abordagem articulada das questões ambientais locais, regionais, nacionais e globais. (Lei Federal 9.795/1999).

A região de Bonito adota o ecoturismo; nesse sentido, o trabalho com a educação ambiental torna-se um princípio básico para o desenvolvimento sustentado da região, de modo que a comunidade local se beneficie duplamente: ter uma cidade valorizada pelo tipo de turismo que oferece e ainda poder exercer as práticas ambientalmente corretas disseminadas pela educação ambiental.

Uma vez que uma parcela significativa da base econômica do município está vinculada à prática do ecoturismo, a educação ambiental encontra-se intrínseca neste processo que vai desde a capacitação dos profissionais que atuam nesse segmento, elaboração e divulgação de materiais informativos sobre a fauna, flora, geografia da região, orientações prévias realizadas pelos guias sobre os locais a serem visitados, prêmios concedidos à região, bem como a divulgação das pesquisas científicas realizadas, dentre outros.

As atividades mais avançadas de ecoturismo incluem um trabalho de educação ambiental com ajuda de guias especializados, painéis interpretativos, entre outros. O desenvolvimento de roteiros e programas diferenciados a vários tipos de ambientes, quando associado à transmissão de um conjunto organizado de informações e conceitos, leva com relativa facilidade ao aprendizado. Nesse caso, o grande legado deixado ao turista consiste na compreensão da ecologia local e consciência da importância de se preservar o ambiente natural, assim como a história e a cultura dos lugares de visitação. (SALGADO, 2007).

O objetivo deste trabalho é discutir a interrelação da prática do ecoturismo com a educação ambiental em quatro atrativos - Buraco das Araras, Gruta do Lago Azul, Baía Bonita e Rio Formoso - situados entre os municípios de Jardim e Bonito, na região da Serra da Bodoquena, em Mato Grosso do Sul.

\section{MATERIAL E MÉTODOS}

\section{Área de Estudo}

A Serra da Bodoquena assentada em rochas carbonáticas - calcários e dolomitos - constitui um planalto escarpado a oeste, no sentido da Planície do Pantanal, e suavemente inclinado a leste, onde transiciona para a planície de inundação do Rio Miranda. Apresenta-se alongado no sentido norte-sul, com cerca de $300 \mathrm{~km}$ de comprimento e largura variando de 20 a $50 \mathrm{~km}$. O Planalto apresenta sua conformação superficial com forte influência das estruturas tectônicas relacionadas à Faixa de Dobramentos do Paraguai, onde as camadas foram intensamente dobradas na porção oriental, na forma de dobras isoclinais associadas à falhas de empurrão com vergência para oeste, no sentido do Bloco Rio Apa. Já a oeste de Bonito, no interior do Planalto, as camadas encontram-se na forma de dobras abertas, com destaque para os sinclinais do Rio Perdido e do Rio Salobra. Em função dessa estruturação tectônica, a porção central do Planalto é caracterizada por um maciço rochoso elevado onde predominam exposições dos calcários calcíticos da Formação Tamengo. (MERCANTE, 2005). 
De acordo com a Fundação Neotrópica do Brasil (2005) citada no Zoneamento Econômico Ecológico do MS (ZEE/MS), de 2009, a Serra da Bodoquena encontra-se inserida na Bacia Hidrográfica do Rio Miranda e ocupa uma posição estratégica para a conexão dos biomas Mata Atlântica, Cerrado e Pantanal. Tida como área de prioridade extremamente alta para conservação no Mapa das Áreas Prioritárias para a Conservação, de Utilização Sustentável e Repartição de Benefícios da Biodiversidade Brasileira (MMA, 2002; MMA, 2007); zona núcleo da Reserva da Biosfera do Pantanal, cuja principal função é assegurar a proteção da biodiversidade (RBMA, 2007) e; integração do Corredor de Biodiversidade Miranda - Serra da Bodoquena, que visa à manutenção de um corredor entre os biomas: cerrado e pantanal.

Segundo a Secretaria de Estado de Meio Ambiente, das Cidades, do Planejamento, da Ciência e Tecnologia de Mato Grosso do Sul (SEMAC-MS), o município de Bonito está localizado a $297 \mathrm{~km}$ de
Campo Grande e $238 \mathrm{~km}$ de Jardim, ambos fazem parte da Microrregião Geográfica de Bodoquena (MRG 09), localizados no sudoeste de Mato Grosso do Sul, com coordenadas $21^{\circ} 07^{\prime} 16^{\prime}$ "de Latitude Sul e $56^{\circ} 28^{\prime} 55^{\prime \prime}$ de Longitude Oeste.

O município de Bonito possui limite com os municípios de Bodoquena ( $\mathrm{N}$ e NO), Miranda (N), Anastácio (NE), Nioaque (E), Guia Lopes da Laguna (SE), Jardim (S) e Porto Murtinho (SO e O). De acordo com os dados do IBGE (2007), o município abriga uma população de 17.275 habitantes, o que corresponde a uma densidade demográfica de 3,501 hab $/ \mathrm{km}^{2}$.

Já o município de Jardim faz divisa com os municípios de Bonito (N), Guia Lopes da Laguna (NE e E), Ponta Porã (SE), Bela Vista (S), Caracol (SO) e Porto Murtinho (O e NO). Possui uma população de 23.341 (IBGE, 2007), com uma densidade demográfica de 10. $601 \mathrm{hab} / \mathrm{km}^{2}$. A Figura 1 mostra a localização dos municípios de Bonito e Jardim no contexto nacional e regional.

Figura 1: Localização dos municípios de Bonito e Jardim, MS.

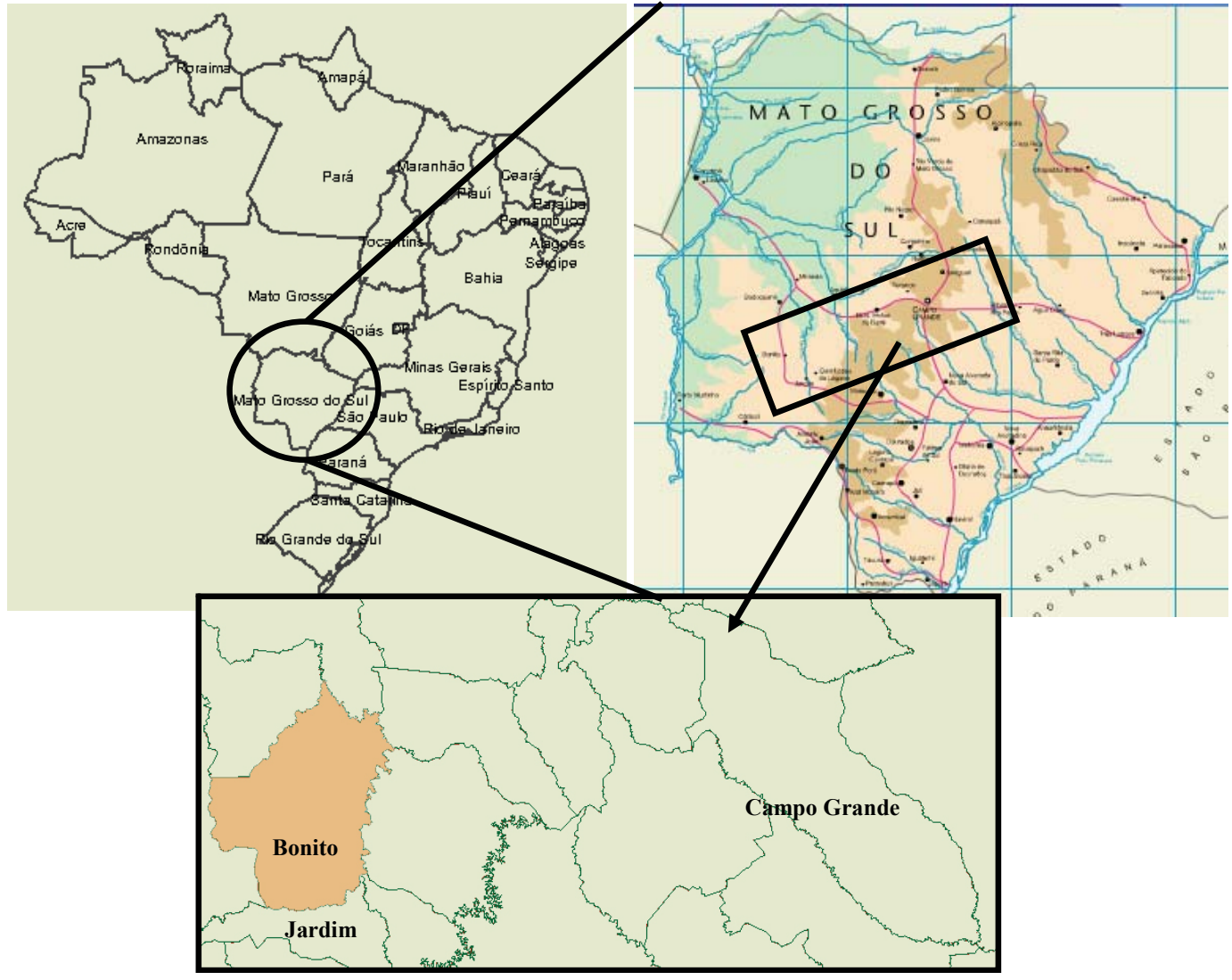

Fonte: http://mapas.ibge.gov.br/website/divisao/viewer.htm 
A região de Bonito está localizada em uma área de contato de diferentes tipos e grupos litológicos, com intensos processos tectônicos, implicando na produção de paisagens particulares. Está assentada basicamente sobre rochas carbonáticas - calcários e dolomitos - das Formações Cerradinho e Bocaina, do grupo Corumbá, no topo, e rochas do Grupo Cuiabá, na base, arcabouço geológico da Serra da Bodoquena. (DIAS, 2000).

As formações vegetais identificadas na região são a Floresta Estacional Semi-Decidual, nas partes de relevo mais elevadas, Floresta Estacional Semi-Decidual Ribeirinha, Floresta Estacional Decidual, as quais apresentam espécies cênicas divulgadas entre os visitantes como atrativos para o turismo como aroeira (Myracrodruon urundeuva), peroba (Aspidosperma polyneuron), angico (Parapiptadenia rígida), jatobá (Hymenaea stigonocarpa), cerejeira (Eugenia involucrata), figueiras (Ficus sp.), ipê-roxo (Tabebuia avellanedae) e amarelo (Tabebuia alba), orquidáceas, bromeliáceas e briófitas.

De acordo com o Zoneamento Econômico e Ecológico do MS, ao mesmo tempo em que a Serra da Bodoquena apresenta possibilidades de se tornar polo minerário, pela descoberta de ocorrência de reservas significativas de mármore, calcário e fosfato, sua formação geológica aponta importantes perspectivas de descobertas de sítios arqueológicos e a existência de sistemas de caverna de grande valor científico, turístico e ambiental, e sua ocupação, principalmente na região de Bonito resultou na sua consagração como grande destino eco turístico de relevância internacional. (MS, 2009).

Nessa perspectiva, o estudo da definição dos locais de representatividade deu-se considerando a presença de potencialidades singulares do relevo cárstico, com feições e formas que se transformam em atrativos para a prática do ecoturismo, do geoturismo e, até mesmo, do turismo de aventura. Os locais são: Buraco das Araras, Gruta do Lago Azul, Baía Bonita e Rio Formoso.

Esses locais encontram-se enquadrados nas unidades de paisagens identificadas por Dias (2000) na região de Bonito: Unidade Cárstica da Bodoquena, Unidade do Formoso/Perdido, Unidade dos Morros Disjun- tos, Unidade Agrícola, Unidade de Pastagens e perímetro urbano (Bonito). Na Unidade do Formoso/Perdido tem se enquadrado os locais dos atrativos do Rio Formoso e a Baía Bonita. Na Unidade dos Morros Disjuntos tem-se como local de destaque a Gruta do Lago Azul.

$O$ roteiro de visita técnica na região de Bonito foi elaborado com vistas a possibilitar conhecer locais, com expressivos recursos naturais, que são atrativos para a prática do ecoturismo e geoturismo. A delimitação levou em conta suas especificidades ambientais e suas formações, sendo de caráter relevante para fins de educação ambiental.

$\mathrm{Na}$ fase de planejamento, recorreu-se ao uso de imagens tiradas via satélites, sendo que o processamento digital da imagem foi elaborado no Laboratório de Geoprocessamento da Anhanguera Uniderp com a utilização do software Imagine Erdas. De acordo com a imagem de satélite LANDSAT 5 (RGB 543), demonstra-se a localização do objeto desse estudo, conforme Figura 2.

O trabalho de campo, uma atividade presente na construção do conhecimento, assume importância para a contextualização tanto na pesquisa como no ensino, por envolver, em ambos os casos, a investigação científica. Esse procedimento, no entanto, não é exclusivo de uma ciência, posto que dele se apossam as mais diferentes áreas do conhecimento sejam as ciências exatas, da terra ou sociais. (SUERTEGARAY apud MERCANTE, 2005).

O trabalho de campo foi realizado em julho de 2010 para verificações in loco dos atrativos definidos e dos elementos indicativos para o ecoturismo, mediante cronograma de atividades. Como instrumento de pesquisa recorreu-se ao registro fotográfico com máquinas digitais e anotações em cadernetas de campo.

A visita em cada local teve o acompanhamento de guias turísticos, credenciados pelo Ministério de Turismo. Houve, ainda, participação dos pesquisadores em palestra ministrada pelo Diretor da Secretaria de Turismo, Indústria e Comércio de Bonito - Clayton Castilho Gomes e pelo Secretário Municipal do Meio Ambiente - Edmundo Costa Junior com a abordagem das formas de organização do turismo na região. 
Figura 2: Imagem de satélite LANDSAT 5 (RGB 543), com identificação das paisagens

Anhanguera - UNIDERP

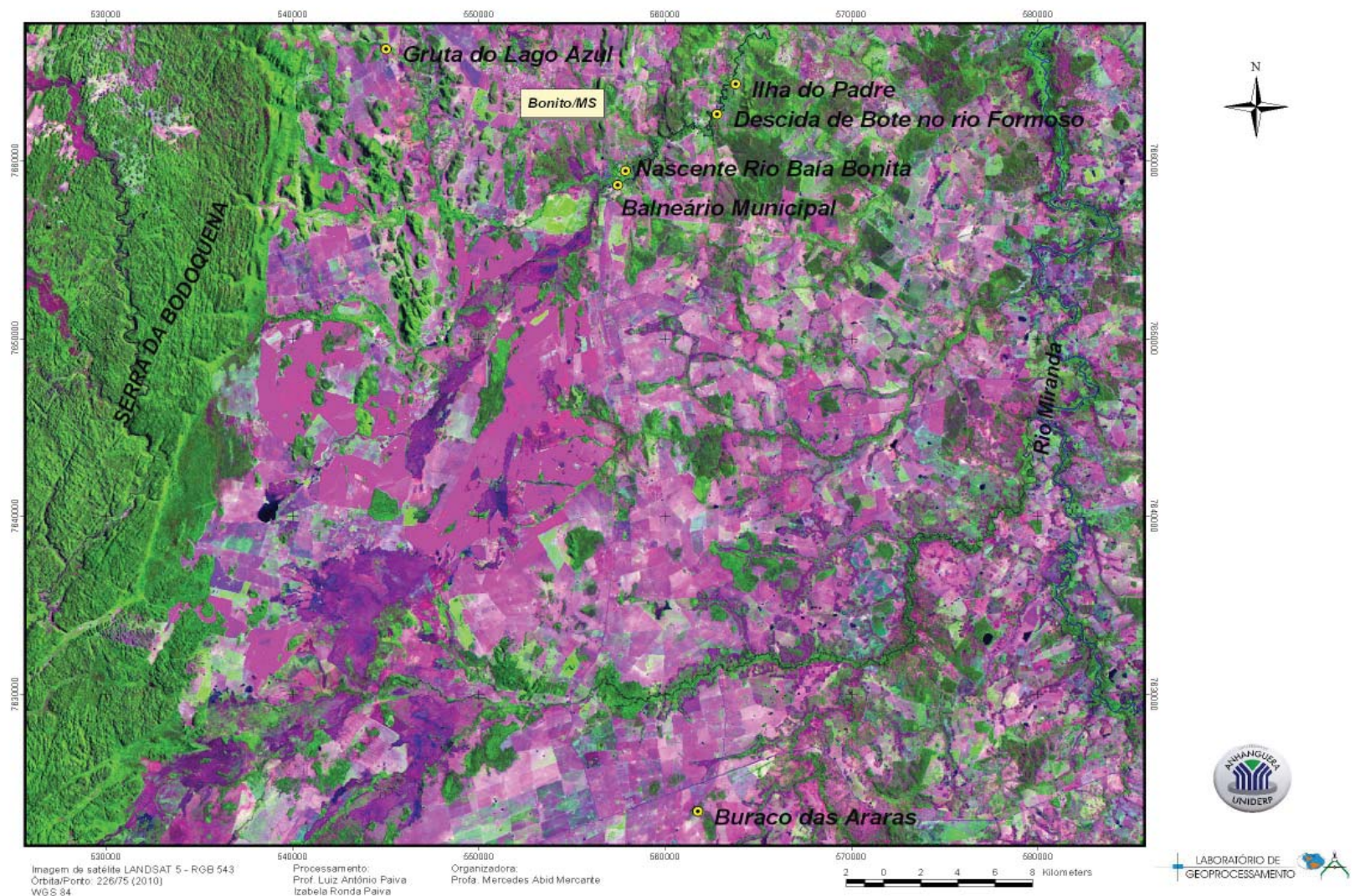

Fonte: Laboratório de Geoprocessamento

Legenda: 1- Buraco das Araras, 2 - Gruta do Lago Azul, 3 - Rio Formoso, 4 - Nascente Rio Baía Bonita.

\section{RESULTADOS E DISCUSSÕES}

O Quadro 1 retrata as características ambientais analisadas neste estudo.

O Buraco das Araras, situada na Fazenda Alegria, em Jardim, é considerado Reserva Particular do Patrimônio Natural (RPPN), com área de 29,0348 ha. A visitação, por meio de uma trilha circular de 900 metros, é realizada por grupos de no máximo 10 pessoas com intervalos de 15 minutos para novas saídas. Possui licença ambiental para operação de 220 visitantes/dias, trabalham com aproximadamente 160 visitantes/dia.

No Buraco das Araras percebeu-se que a vegetação de entorno está em fase pioneira de regeneração e, nas fazendas lindeiras, a ocupação com pastagens exógenas (principalmente Brachiaria $s p$ ) chega até o limite divisório com a Reserva Particular do Patrimônio Cultural (RPPN). Nesse ponto falta, ainda, a conscientização desses vizinhos e tempo para que a regeneração florística dentro da RPPN alcance estádios regenerativos mais avançados. 
Educação ambiental e o ecoturismo na Serra da Bodoquena em Mato Grosso do Sul Fernando Machado Klein, Juliana P. de Oliveira Escandolhero, Nilce Romero Lucchese, Mercedes Abid Mercante, Silvio Fávero, Silvio Carlos Rodrigues

Quadro 1; Características ambientais dos locais dos atrativos da região de Bonito.

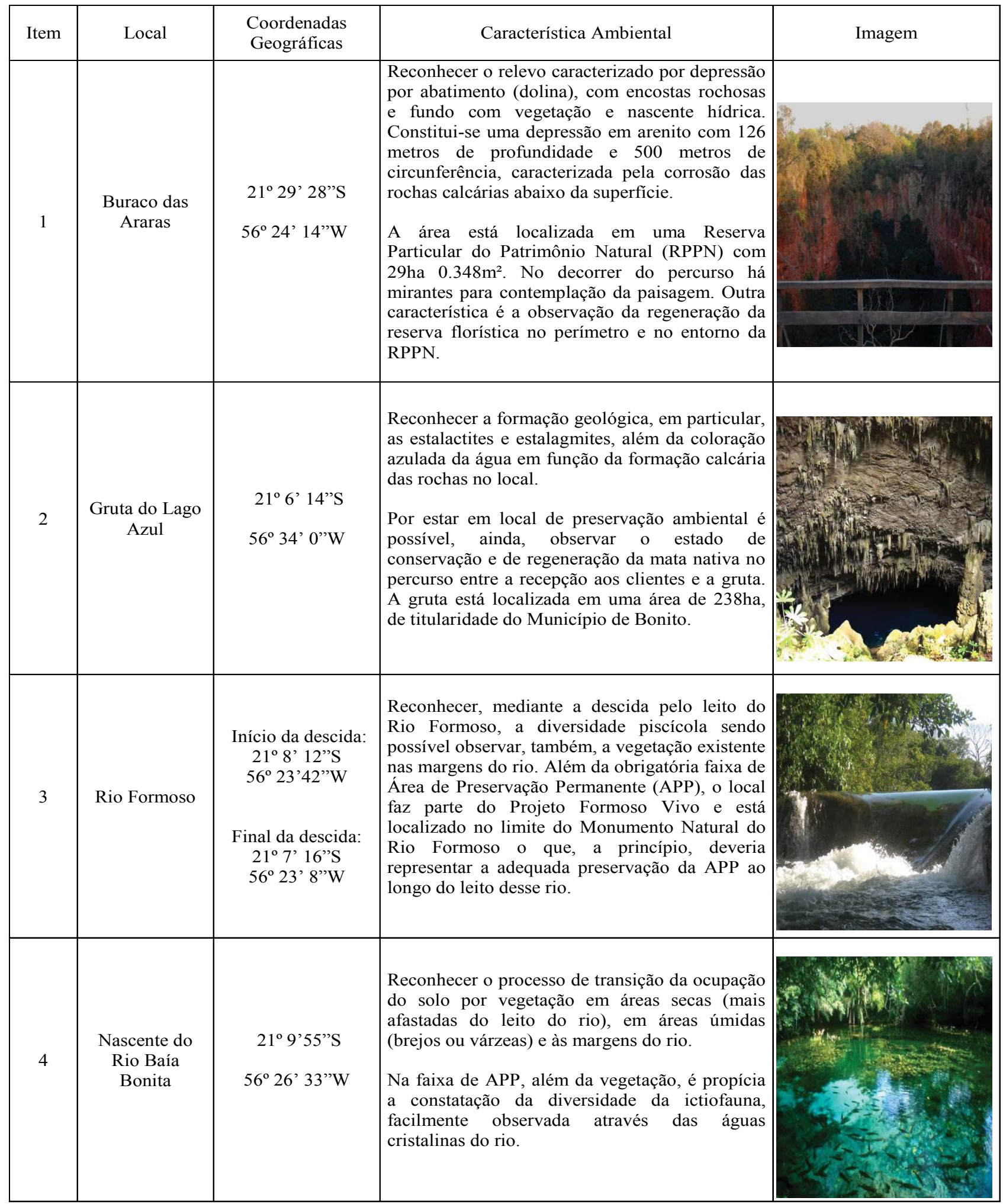

Fonte (imagens): Fernando Machado Klein e Nilce Romero Lucchese - arquivo pessoal - 2010. 
Durante o percurso até os mirantes, o guia turístico informou de como foi criada a RPPN do Buraco das Araras, da importância da unidade de conservação para preservação das araras na região e apresentou dados do crescimento da população dessa ave que passou a ter, principalmente, um local para reprodução livre de ameaças externas ao meio. Durante o percurso são fornecidas informações sobre os trabalhos iniciais de "limpeza" da dolina que antes era usada como "lixão" e desova de carros e corpos humanos. Destaca-se, também, a importância da regeneração da mata nativa no entorno da depressão e do trabalho de convencimento que os proprietários tentam fazer com os donos das fazendas lindeiras à RPPN para que mantenham o entorno da reserva também preservada. Apesar do bom histórico fornecido, percebe-se que não há o preparo para o repasse de informações mais técnicas sobre a formação geológica em si, como foi originada, que tipo de rocha e relevo compõe a paisagem observada.

Tanto a Gruta do Lago Azul como o rio Formoso são unidades de proteção integral, pertencentes ao Sistema Nacional de Unidades de Conservação (SNUC), constituindo-se como Monumentos Naturais estaduais visando preservação de sítios naturais raros, singulares e de grande beleza cênica.

Na gruta do Lago Azul são repassadas orientações por guia turístico credenciado, sendo fornecido material de proteção individual composto por toca e capacete. Na trilha para a gruta pode-se observar que a vegetação do local possui estágio pioneiro de regeneração. Houve o cuidado de se preparar o piso da trilha com pedra britada para não carrear sedimentos para a região da gruta. $\mathrm{Na}$ entrada há explicações que vão até o ponto final da descida. Ao todo são três pontos de parada e observação para as formações de estalactites e estalagmites, além do lago formado no fundo da gruta, que assume a coloração azulada dada a composição calcária da água e a reflexão da luz. $\mathrm{O}$ passeio permitiu um bom aproveitamento educacional, que possibilitou na prática a formação e a evolução da paisagem no ambiente de uma gruta. Quase toda a ênfase do passeio é destinada à gruta e ao lago, pouco se divulgando que o local está situado em um Monumento Ambiental, com características de ocupação e de exploração bem definidas.

A Gruta do Lago Azul, tombada pelo Insti- tuto do Patrimônio Histórico e Artístico Nacional (IPHAN), em 1978, é o ponto turístico mais visitado da região. A origem do seu nome encontra-se pela aparente coloração de suas águas cristalinas quando da penetração da luz solar. O limite de visitantes/dia é de 305 pessoas, em grupos de no máximo 15 pessoas, além do guia. $\mathrm{O}$ intervalo entre um grupo e outro é de no mínimo 20 minutos e o máximo permitido dentro da gruta é de 4 grupos ou 60 pessoas de uma só vez.

O município de Bonito tem instituído o projeto Formoso Vivo que visa a recuperação da vegetação nativa nas Áreas de Preservação Permanente (APP) ao longo do rio Formoso. Durante o percurso de descida do mesmo é possível observar a grande quantidade e diversidade piscícola, além de alguns pequenos mamíferos e aves nas árvores ribeirinhas. Destaca-se, porém, que em vários pontos é claramente perceptível o não cumprimento da largura mínima, entre $50 \mathrm{~m}$ e $100 \mathrm{~m}$, de preservação de vegetação nativa para a APP às margens do Rio Formoso. Do leito do rio é possível observar que há fazendas que ainda utilizam parte dos segmentos que deveriam ser destinados à APP para a ocupação com pastagem de Brachiaria $s p$. Essa ocupação irregular favorece o carreamento de sedimentos para o leito do rio, vindo das fazendas. Não foi observado, contudo, nenhum ponto onde pudesse haver o acesso de gado para dessedentação diretamente no rio.

A Lei Orgânica do Município de Bonito estabelece aos rios do município, mesmo aqueles de largura inferior a dez metros, uma área de preservação permanente equivalente a 50 metros. Mais restritiva é a Lei Estadual 1871/1998, que cria uma faixa de proteção especial de 150 metros para cada margem dos rios pertencentes à bacia do Rio Formoso e do Rio da Prata e estabelece normas de uso. A Lei Municipal 989/2003 estabelece, ainda, restrições ambientais e transforma em rios-cênicos os rios das bacias do Formoso, Prata e Peixe.

Devido ao seu grande potencial turístico, a faixa de preservação do Rio Formoso foi amplamente ocupada pela atividade turística nas últimas décadas. Em muitos casos essa ocupação foi mal planejada levando à sérias intervenções que descaracterizaram os ambientes naturais das margens do rio. Edificações como casas, galpões, quiosques, churrasqueiras, mu- 
ros de arrimo, calçamento de pedra, piscinas de pedra com desvios da água do rio estão entre as principais estruturas encontradas na faixa de APP. (CONSTANTINO, 2004).

A Reserva Ecológica Baía Bonita possui a nascente do Rio Baía Bonita com águas ricas em calcário e diversidade de fauna e flora aquática. A visitação também possui limitação de visitantes/grupo sendo de nove pessoas, mais o guia.

Na nascente do Rio Baía Bonita está localizado o atrativo conhecido como aquário natural, em função das águas cristalinas da nascente que permitem ao turista observar a variedade da fauna aquática mesmo do lado de fora do rio. $\mathrm{O}$ acesso até a nascente, desde a recepção, é feito por meio de tablado elevado de madeira o que impede o pisoteio e compactação do solo pela passagem dos visitantes, além de limitar o trajeto por onde se pode andar. Nesse trajeto é possível observar a transição da vegetação que compõe a APP. Nas proximidades da estrutura de recepção, mais afastado do leito do rio, a vegetação é mais densa, formando mata decídua ou semi-decídua, com solo sujeito a encharcamento esporádico. Antes de se chegar a nascente a trilha passa por várzea com vegetação típica de locais encharcados, de baixa estatura, pouco densa. Mesmo com a paralisação de cortes e intervenções na APP há aproximadamente 10 anos, percebe-se que a vegetação nativa está ainda em fase pioneira de regeneração; ao chegar ao entorno da nascente, percebe-se um ambiente bem preservado e com grande variedade biológica.

O trabalho dos guias influencia diretamente na satisfação do turista, tornando necessário não só os conhecimentos técnicos ou explícitos relativos ao passeio e às características próprias de atendimento ao público, como também o conhecimento tácito que estes adquirem pela experimentação da atividade. (SALGADO, 2007).

O trabalho de campo demonstrou que a diversificação dos locais observados, sejam pelo processo de ocupação humana ou pela alteração do meio físico, pode ser interpretada mediante observação e experimentação por especialistas de diferentes áreas do conhecimento, sendo um campo vasto para o desenvolvimento de inúmeras pesquisas.

Face à complexidade dos problemas, cada vez mais é necessária a comunicação entre as diversas áreas e saberes, ou seja, a interdisciplinaridade, uma exigência para que os resultados sejam significativos e envolvam todas as vertentes ambientais. (LEFF, 2001).

É importante ressaltar que, atualmente, apesar do objetivo principal ser a venda de passeios pelos atrativos, o ecoturismo pode proporcionar o aproveitamento desta ação como veículo de educação ambiental, o que o torna uma das formas para a conscientização e disseminação de práticas de conservação ambiental.

\section{CONSIDERAÇÕES FINAIS}

O sistema turístico instituído no município de Bonito, segundo o Conselho Municipal de Turismo de Bonito (COMTUR), pode ser visto como fator limitador por seus aspectos restritivos, mas é essencial para a manutenção da prática do turismo responsável e da preservação dos recursos naturais existentes na região. A denominação sistema justifica-se por envolver uma cadeia produtiva formada por prestadores de serviços que envolvem alimentação, transporte, hospedagem, agenciamento, guias de turismo, souvenirs, entre outros.

O município de Bonito, para fins de controle e sistematização da atividade turística, adota um documento denominado voucher, criado em 1995, de uso obrigatório pelos turistas para acesso aos atrativos. Conforme definição da Secretaria Municipal de Turismo, Indústria e Comércio, o voucher-único é um documento fiscal de arrecadação e controle dos serviços turísticos municipais.

Em Bonito e Jardim é obrigatório o acompanhamento por guias em todos os passeios turísticos e em qualquer atividade cultural ou científica em áreas turísticas de domínio público. Os locais que ofertam passeios e atrativos turísticos na região possuem suas respectivas licenças ambientais.

Porém, a Licença de Operação não basta para proteger os ambientes. Existe forte pressão do capital sobre os ecossistemas da região de Bonito. Com a construção do aeroporto regional e a inauguração de novos hotéis, que em conjunto facilitarão o acesso à região, haverá maior pressão sobre os ecossistemas locais. Acreditamos que a sustentabilidade de ambientes 
frágeis como as nascentes e rios de Bonito somente será mantida se programas similares de monitoramento e proteção forem adotados nestes ecossistemas e, obviamente, respeitados pelos donos da terra e pelo Poder Público. (SABINO; ANDRADE, 2003).

A educação ambiental envolve ações e práticas educativas voltadas à sensibilização da coletividade sobre as questões ambientais e à sua organização e participação na defesa da qualidade do meio ambiente consorciada com a prática do ecoturismo. Com a prática de campo orientada cientificamente é possível vivenciar a interrelação das condições físicas do local, as formas de relevo e a ocupação do homem instituída nesse ambiente.

É necessário que todos os agentes que compõem o sistema turístico da região, inclusive os moradores dos municípios envolvidos, conheçam e entendam a natureza que os cerca e tenham claro que a preservação e conservação do meio ambiente são de fundamental importância para manutenção da base econômica que atualmente se estabelece: 0 turismo. A compreensão desta importância pode ser proporcionada por meio de ações públicas, a partir de políticas estruturadas pelo município que permitam a adequada abrangência na disseminação das informações pertinentes.

Ressalta-se, também, a necessidade de intensificação de ações de cunho educacional, principalmente, aos guias de turismo, por serem os principais indutores e difusores de informações relativas ao meio ambiente. As informações devem ser tratadas num contexto amplo e não repassadas de forma fragmentada aos visitantes, permitindo uma melhor compreensão da relevância ambiental da região.

Sugere-se também um estudo mais aprofundado dos percursos ofertados, com respectiva avaliação do potencial educativo e mapeamento da caracterização e adequação destes percursos relacionando-os com seus atrativos para diferentes públicos e visitantes.

Salienta-se que há necessidade de intensificação de ações de promoção do desenvolvimento de metodologias e sistemas de acompanhamento, avaliação e aperfeiçoamento do ecoturismo na região como forma de mensurar seus impactos diretos e indiretos, inclusive de indutores de uma educação ambiental. A educação ambiental é comemorada como um dos produtos do ecoturismo, mas também deve ser compreendida como fator potencializador das ações preservacionistas relativas à prática do ecoturismo. Em se sabendo desta relação, o desafio está posto à região de Bonito.

\section{AGRADECIMENTOS}

Ao Programa Nacional de Cooperação Acadêmica e Cooperação de Aperfeiçoamento Profissional de Nível Superior CAPES/PROCAD (Projeto 067-2007), à Universidade Federal de Uberlândia e Universidade Anhanguera-UNIDERP pelo apoio a realização do trabalho.

\section{REFERÊNCIAS}

BONITO. Lei Orgânica do Município de Bonito. 5 abr. 1990.

. LEI $n^{\circ}$. 989. Estabelece limitações ambientais como forma de conservação de natureza, proteção do meio ambiente e defesa das margens nas áreas das bacias hidrográficas dos Rios Formoso, Prata e Peixe, no município de Bonito - MS, 9 dez. 2003.

BRASIL. DECRETO $n^{\circ}$. 4.340. Regulamenta artigos da Lei ${ }^{\circ}$ 9.985, de 18 de julho de 2000, que dispõe sobre o Sistema Nacional de Unidades de Conservação da Natureza - SNUC, e dá outras providências, 22 ago. 2002.

Lei $n^{\circ}$ 9.795. Dispõe sobre a educação ambiental, institui a Política Nacional de Educação Ambiental e dá outras providências, 27 abr. 1999.

Lei $n^{\circ}$ 9.985. Regulamenta o art. $225, \S 10$, incisos I, II, III e VII da Constituição Federal, institui o Sistema Nacional de Unidades de Conservação da Natureza e dá outras providências, 18 jul. 2000.

CONSTANTINO, R. et al. Projeto Formoso Vivo: uma estratégia integrada para conservação da bacia hidrográfica do Rio Formoso. Bonito, MS: [s.n.], 2004.

DIAS, JAILTON. A região cárstica de Bonito, MS: 
Educação ambiental e o ecoturismo na Serra da Bodoquena em Mato Grosso do Sul Fernando Machado Klein, Juliana P. de Oliveira Escandolhero, Nilce Romero Lucchese, Mercedes Abid Mercante, Silvio Fávero, Silvio Carlos Rodrigues

uma proposta de zoneamento geoecológico a partir de unidades de paisagem. Ciência Geográfica. Bauru: [s.n.], n. 1, jan./ abr. 2000.

LEFF, E. Saber ambiental: sustentabilidade, racionalidade, complexidade, poder. Petrópolis: Vozes, 2001.

MATO GROSSO DO SUL. LEI $n^{\circ}$. 1.871. Estabelece a forma de conservação da natureza, proteção do meio ambiente e defesa das margens nas áreas contíguas aos Rios da Prata e Formoso, e dá outras providências. 15 jul. 1998.

LEI $n^{\circ}$. 2.135. Institui a Política para o Desenvolvimento do Ecoturismo do Estado de Mato Grosso do Sul, e dá outras providências, 14 ago. 2000.

Secretaria de Estado de Meio Ambiente, das Cidades, do Planejamento, da Ciência e da Tecnologia. Zoneamento Econômico Ecológico do MS. 2009. Disponível em: < http://www.semac.ms.gov.br/>. Acesso em: 30 ago. 2010.

MERCANTE, M. A.; PISSINI, L. F.O. M.; ARAÚJO, A. A primazia do uso de conceitos geográficos em estudos interdisciplinares. Anais... do XV Encontro Nacional de Geógrafos, 2005.
SABINO, J.; ANDRADE, L. P. Uso e conservação da ictiofauna no ecoturismo da Região de Bonito, Mato Grosso do Sul: o mito da sustentabilidade ecológica no Rio da Baía Bonito (Aquário Natural de Bonito), 2003. Disponível em: <www.biotaneotropica.org.br>. Acesso em: 30 ago. 2010.

SALGADO, C. M. M. Uso da informação no Desenvolvimento do território turístico de Bonito/MS, 2007. Disponível em: <http:/www.cpap.embrapa.br/teses/ online/DST39.pdf>. Acesso em: 30 ago. 2010.

SALVATI, S. S. Certificação em ecoturismo: lições mundiais e recomendações para o Brasil. Brasília: WWF Brasil, 2001.

SECRETARIA MUNICIPAL DE TURISMO, INDÚSTRIA E COMÉRCIO DE BONITO, MS. Disponível em: <www.bonito-ms.com.br>. Acesso em: 6 ago. 2010.

WEARING, Stephen; NEIL, John. Ecoturismo: impactos, potencialidades e possibilidades. Barueri, SP: Manole, 2001. 